\title{
Growth and Characterization of Dichloro Tris(Triphenyl Phosphine Oxide)Cadmium(II) - Second Harmonic Generation from a Centrosymmetric Crystal
}

\author{
K. Sreevani ${ }^{1}$, K. Thangaraj ${ }^{2 *}$, K. Ramamurthi $^{3}$, S. Selvanayagam ${ }^{4}$, B. Sridhar ${ }^{5}$, \\ V. V. Anierudhe ${ }^{6}$ \\ ${ }^{1}$ Department of Physics, K. S. R. College of Engineering, Tiruchengode, India \\ ${ }^{2}$ Department of Physics, Kongu Engineering College, Perundurai, India \\ ${ }^{3}$ Crystal Growth and Thin Film Laboratory, School of Physics, Bharathidasan University, Tiruchirappalli, India \\ ${ }^{4}$ Department of Physics, Kalasalingam University, Krishnan Koil, India \\ ${ }^{5}$ Laboratory of X-Ray Crystallography, Indian Institute of Chemical Technology, Hyderabad, India \\ ${ }^{6}$ Vidyaa Vikas Educational Institutions, Tiruchengode, India \\ Email: *ksvphy2010@gmail.com
}

Received August 12, 2012; revised September 27, 2012; accepted October 15, 2012

\begin{abstract}
The title compound dichloro tris(triphenyl phosphine oxide)cadmium(II) were grown by slow cooling method from aqueous solution. The title compound was synthesized and purified by repeated crystallization process. Grown crystals were characterized by X-ray diffraction and FTIR analysis. The range of optical transmission was determined by recording UV-Vis-NIR spectrum. Thermal properties were investigated by DTA and TGA analyses. Its mechanical hardness was estimated by Vickers microhardness method.
\end{abstract}

Keywords: Crystal Growth; Single Crystal X-Ray Diffraction; Ultraviolet Spectra; Nonlinear Optical Crystals

\section{Introduction}

Growth of single crystals of semi organics has been a subject of perennial concern in order to use the materials for device application. Due to this, the new semi-organic crystals have higher mechanical strength and chemical stability [1]. Metals with $\mathrm{d}^{10}$ configuration like Zinc, Cadmium, Mercury readily combines with organic materials resulting in stable compounds with good physic chemical behaviour. Triphenylphosphine is an interesting candidate as it binds well to most of the transition metals of group VII-X [2]. The basic structure of organic NLO Materials is based on the $\pi$ bond system, due to the overlap of $\pi$ orbital delocalization of electronic density [3]. On the basis of this, in the present investigation, we report for the first time, the synthesis, growth, crystal structure and characterization of the title compound dichloro tris(triphenyl phosphine oxide)cadmium(II).

\section{Experimental Section}

\subsection{Synthesis of $\mathrm{CdCl}_{2}(\mathrm{TPPO})_{4}$}

The title compound was synthesized by dissolving ana-

${ }^{*}$ Corresponding author. lytical reagent grade cadmium chloride $\left(\mathrm{CdCl}_{2}\right)$ (HIMEDIA) and triphenyl phosphine oxide (TPPO) (Chanshu Yangvan Chemical China) in absolute ethanol in stoichiometric ratio. The temperature of the solution was maintained at about $50^{\circ} \mathrm{C}$ and $\mathrm{CdCl}_{2}(\mathrm{TPPO})_{4}$ was obtained by the evaporation of the solvent. Purity of the compound was increased by successive recrystallization.

$$
\mathrm{CdCl}_{2}+2\left[\left(\mathrm{C}_{6} \mathrm{H}_{5}\right)_{3} \mathrm{PO}\right] \rightarrow \mathrm{CdCl}_{2}\left[\left(\mathrm{C}_{6} \mathrm{H}_{5}\right)_{3} \mathrm{PO}\right]_{4}
$$

\subsection{Crystal Growth}

$\mathrm{CdCl}_{2}$ (TPPO) $)_{4}$ crystals were grown by slow evaporation technique. The precipitate was taken as raw material. Saturated $\mathrm{CdCl}_{2}$ (TPPO) $)_{4}$ solution was prepared at room temperature with ethanol and Dimethyl sulfoxide (DMSO) of 1:1 ratio as solvent. DMSO was added to improve the crystallization. The prepared transparent solution was filtered. The $\mathrm{pH}$ of the solution is 5 . The solution was taken in glass beaker and closed with perforated covers and kept in a dust free atmosphere. The transparent crystals were harvested after 35 days when it attained a size of $7 \times 2 \times 2 \mathrm{~mm}^{3}$. The as grown crystal is shown in Figure 1. 


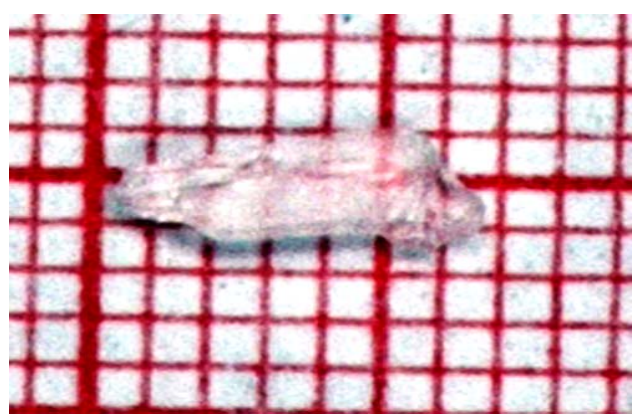

Figure 1. The as grown crystal of dichloro tris(triphenylphosphine oxide)cadmium(II)crystal.

\subsection{Characterization of $\mathrm{CdCl}_{\mathbf{2}}(\mathrm{TPPO})_{4}$}

The single-crystal XRD data of the grown $\mathrm{CdCl}_{2}(\mathrm{TPPO})_{4}$ crystal was obtained using accurate unit cell parameters and orientation matrix were obtained by least-square fit of several high angle reflection in the range $1.5^{\circ} \leq \theta \leq$ $25^{\circ}$ using $\mathrm{Mo}_{\alpha}$ radiation on BRUKER SMART APEX $\mathrm{CCD}$ area detector using $\omega$ scan mode. X-ray powder pattern of the crystal was recorded on a Rigaku DMaxic computer controlled X-ray powder diffractometer with copper (K alpha 1) radiation of wavelength $1.54056 \AA$. The scanning rate was maintained at $1.6 \%$ min over a $2 \theta$ range of $10^{\circ}$ to $70^{\circ}$ employing reflection mode of scanning. The elemental analysis of the synthesized $\mathrm{CdCl}_{2}(\mathrm{TPPO})_{4}$ was carried out by JSM energy dispersive $\mathrm{X}$-ray microanalyzer equipped with JEOL-6360 SEM.

The functional groups of vibration of $\mathrm{CdCl}_{2}(\mathrm{TPPO})_{4}$ crystal were identified by FTIR technique using a Perkin Elmer spectrophotometer using $\mathrm{KBr}$ pellet technique in the range of $400-4000 \mathrm{~cm}^{-1}$. The UV-Vis-NIR absorption spectrum of the $\mathrm{CdCl}_{2}$ (TPPO) $)_{4}$ crystal was examined in the wavelength range of $450-1000 \mathrm{~nm}$ using Lambda 35 (Instrument Model) UV-Vis-NIR spectrophotometer. Thermogravimetric analysis was carried out for the as grown crystals of $\mathrm{CdCl}_{2}$ (TPPO) $)_{4}$ using PYRIS thermal analyzer. The NLO property of $\mathrm{CdCl}_{2}$ (TPPO) $)_{4}$ crystal was confirmed by Kurtzpowder SHG test using Nd-YAG laser $(1064 \mathrm{~nm})$. The pulse width and repetition rate of the laser pulses were $8 \mathrm{~ns}$ with a repetition rate of $10 \mathrm{~Hz}$ respectively at $1064 \mathrm{~nm}$ radiation. The microhardness studies of single crystal was carried out using a Vickers microhardness tester fitted with a diamond pyramidal indentor.

\section{Results and Discussions}

\subsection{X-Ray Diffraction Analysis}

Unit cell parameters of the grown $\mathrm{CdCl}_{2}$ (TPPO) $)_{4}$ crystals were obtained using the single crystal diffractometer and are given in Table 1. It is found that $\mathrm{CdCl}_{2}$ (TPPO) $)_{4}$ crystallizes in orthorhombic system with centrosymmetric space group Pbca and $\mathrm{V}=6608.4(7) \AA^{3}$. The crystallinity of the grown crystals was checked by taking the X-ray diffraction pattern of powder samples of $\mathrm{CdCl}_{2}$ (TPPO) $)_{4}$. The ORTEP plot of the molecule is shown in Figure 2.

\subsection{Energy Dispersive X-Ray Analysis}

The determination of elemental composition of the single crystal was done using energy dispersive analysis for confirming stoichiometry. The energy spectrum of the crystal is shown in Figure 3. In the present study, the grown $\mathrm{CdCl}_{2}$ (TPPO) $)_{4}$ single crystal was analyzed by JSM energy dispersive X-ray micro analyzer equipped with JEOL-6360 SEM. The energy spectrum confirms the presence of cadmium chloride and triphenyl phosphine oxide.

\subsection{Fourier Transform Infrared (FTIR) Analysis}

The Fourier Transform Infrared spectrum (FTIR) of

Table 1. Single crystal X-ray data of $\mathrm{CdCl}_{2}(\mathrm{TPPO})_{4}$.

\begin{tabular}{cc}
\hline CCDC Number & CCDC 893123 \\
\hline Empirical formula & $\mathrm{C}_{72} \mathrm{H}_{60} \mathrm{Cd}_{2} \mathrm{Cl}_{4} \mathrm{O}_{4} \mathrm{P}_{4}$ \\
Formula weight & 1479.68 \\
Crystal system & Orthorhombic \\
Space group & Pbca \\
& $\mathrm{a}=11.1658(7) \AA ; \alpha=90^{\circ}$. \\
Unit cell dimensions & $\mathrm{b}=22.0016(14) \AA ; \beta=90^{\circ}$. \\
& $\mathrm{c}=26.8999(16) \AA ; \gamma=90^{\circ}$. \\
\hline
\end{tabular}

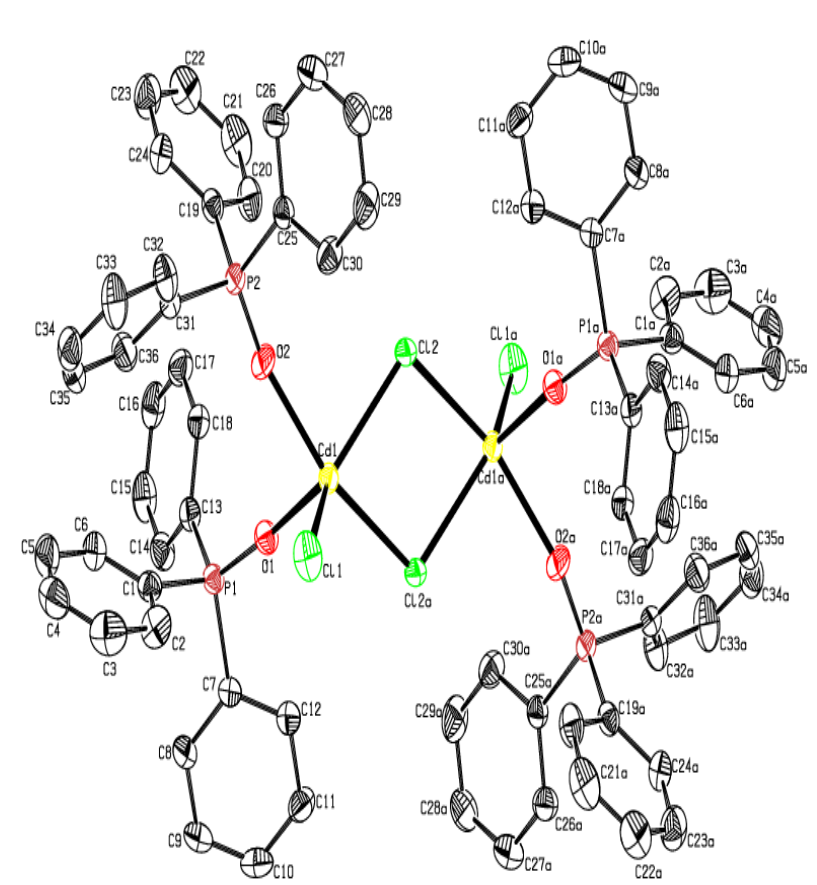

Figure 2. ORTEP plot of the molecule drawn at $30 \%$ probability level. 


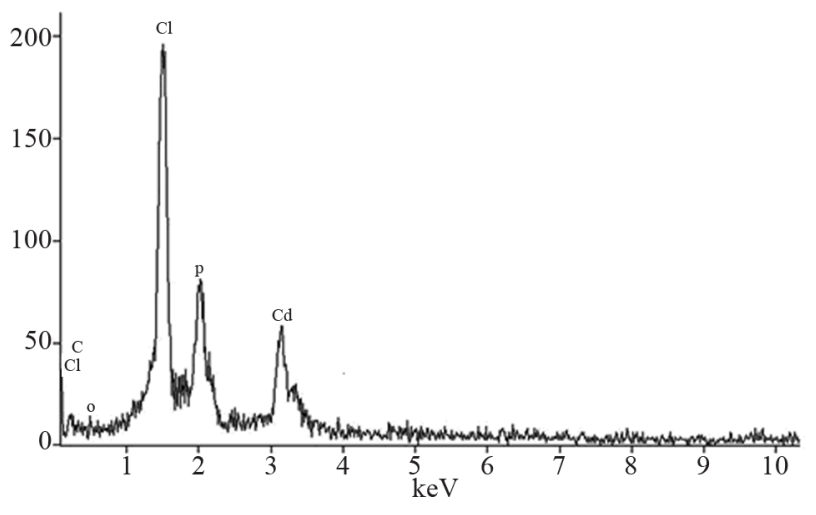

Figure 3. Energy spectrum of dichloro tris(triphenyl phosphine oxide)cadmium(II)single crystal.

$\mathrm{CdCl}_{2}$ (TPPO) $)_{4}$ crystal was recorded on PerkinElmer FTIR spectrophotometer using $\mathrm{KBr}$ pellet technique in the range of $400-4000 \mathrm{~cm}^{-1}$. The recorded FTIR spectrum of $\mathrm{CdCl}_{2}$ (TPPO) $)_{4}$ depicts that stretching vibration of $\mathrm{P}=\mathrm{O}\left(\sim 1187 \mathrm{~cm}^{-1}\right)$ shifts to lower frequency $(\sim 1160$ $\mathrm{cm}^{-1}$ ) which clearly indicates influence of Cd. Also, frequency $537 \mathrm{~cm}^{-1}$ indicates the influence of metal-oxygen vibrational modes [4]. The peak at $3456 \mathrm{~cm}^{-1}$ is assigned for the stretching vibrations of the $\mathrm{O}-\mathrm{H}$ bond of the water molecules absorbed by $\mathrm{KBr}$. The vibrational frequencies of $\mathrm{CdCl}_{2}$ (TPPO) $)_{4}$ are compared with that of the FTIR spectrum of $\mathrm{ZnCl}_{2}$ (TPPO) $)_{2}$ [5] and $\mathrm{CdBr}_{2}$ (TPPO) $)_{2}$ [6] in Table 2.

\subsection{UV-Vis-NIR Analysis}

The absorption spectrum of $\mathrm{CdCl}_{2}$ (TPPO) $)_{4}$ was recorded in the wavelengths range of $450-1000 \mathrm{~nm}$ using Lambda 35 (Instrument Model). UV-Vis-NIR spectrometer. A crystal with the thickness of about $2 \mathrm{~mm}$ was used for this measurement. From the spectrum, it is evident that the compound has a very low cut off at $\sim 390 \mathrm{~nm}$, and the crystal is found to be transparent in the region of 350 $900 \mathrm{~nm}$, which is an essential requirement for frequency doubling process.

\subsection{Thermal Analysis}

Thermogravimetric and differential thermal analysis of $\mathrm{CdCl}_{2}$ (TPPO) $)_{4}$ were carried out using a PYRIS thermal analyzer. A ceramic crucible was used for heating the sample and the analyses was carried out in an atmosphere of nitrogen at a heating rate of $10 \mathrm{~K} / \mathrm{min}$ in the temperature range of $309-1136 \mathrm{~K}$. The initial mass of the material subjected to analysis was $4.5 \mathrm{mg}$. A sharp endothermic peak at $\sim 463 \mathrm{~K}$ depicts a phase transition of the material. Thermal studies show that the crystal is stable without decomposition upto $\sim 573 \mathrm{~K}$ and an endothermic peak observed at $\sim 723 \mathrm{~K}$ represents the melting point of $\mathrm{CdCl}_{2}(\mathrm{TPPO})_{4}$.
Table 2. Comparison of vibrational frequencies $\left(\mathrm{cm}^{-1}\right)$ of $\mathrm{CdCl}_{2}\left(\mathrm{TPPO}_{4}\right.$ with reported works.

\begin{tabular}{|c|c|c|c|}
\hline Assignments & $\begin{array}{c}\mathrm{ZnCl}_{2}(\mathrm{TPPO})_{2} \\
{[5]}\end{array}$ & $\begin{array}{c}\mathrm{CdBr}_{2}(\mathrm{TPPO})_{2} \\
{[6]}\end{array}$ & $\begin{array}{l}\mathbf{C d C l}_{2}(\mathrm{TPPO})_{4} \\
\text { (present work) }\end{array}$ \\
\hline$v(\mathrm{P}=\mathrm{O})$ & 1155 & 1157 & 1160 \\
\hline$v(\mathrm{P}-\mathrm{C})$ & 1437 & 1432 & 1433 \\
\hline$v(\mathrm{C}=\mathrm{C})$ & 1588 & 1589 & 1586 \\
\hline$v(\mathrm{C}-\mathrm{H})$ & 3055 & 3052 & 3058 \\
\hline$v(\mathrm{O}-\mathrm{H})$ & 3436 & 3456 & 3458 \\
\hline
\end{tabular}

\subsection{Microhardness Studies}

Vickers microhardness test was carried out on the prominent face of $\mathrm{CdCl}_{2}$ (TPPO) $)_{4}$ crystal using microhardness tester fitted with a diamond indenter. The indentation was made using a Vickers Pyramidal indentor for various loads. The indentation time was kept at $25 \mathrm{~s}$ for all the loads. From the Vicker's microhardness studies, it is observed that at lower load, there is an increase in the work hardening of the surface layers. For load above $70 \mathrm{~g}$ crack started developing around the indentation mark, which may be due to the release of internal stresses [7].

\subsection{NLO Activity}

The study of SHG conversion efficiency of the grown crystal was carried out using the modified experimental setup of Kurtz and Perry [8]. A Q-switched Nd-YAG laser beam of wavelength $1064 \mathrm{~nm}$, with an input power of $4.9 \mathrm{~mJ}$, and pulsewidth of $8 \mathrm{~ns}$ with a repetition rate of $10 \mathrm{~Hz}$ was used. The grown single crystal of was powdered with a uniform particle size and then packed in a microcapillary of uniform bore and exposed to lase radiations. The output from the sample was monochromated to collect the intensity of $532 \mathrm{~nm}$ component. The generation of the second harmonics was confirmed by the emission of green light. A sample of potassium dihydrogen phosphate (KDP), also powdered to the same particle size of the experimental sample, was used as the reference material in the present measurement. Second harmonic generation efficiency of the powdered $\mathrm{CdCl}_{2}$ (TPPO) $)_{4}$ is $\sim 0.94$ times that of potassium dihydrogen phosphate. The comparison of conversion efficiency of $\mathrm{CdCl}_{2}$ (TPPO) $)_{4}$ has been compared with other reported centrosymmetric materials and is given in Table 3.

\section{Conclusion}

Optical quality single crystals of dichloro tris(triphenyl phosphine oxide)cadmium(II) $\left.\left(\mathrm{CdCl}_{2} \text { (TPPO) }\right)_{4}\right)$ have been grown from aqueous solution by slow cooling method. The lattice parameters have been calculated by X-ray diffraction studies. Elemental analysis of the synthesized 
Table 3. Comparitive study of SHG efficiencies of different centrosymmetric crystals.

\begin{tabular}{ccc}
\hline Compound & Space group & $\begin{array}{c}\text { SHG SHG efficiency in } \\
\text { comparison with } \\
\text { KDP(in times) }\end{array}$ \\
\hline $\begin{array}{c}\text { R,S-serine [9] } \\
\text { (p-Nitrophenol, } \\
\text { hexamethyltetramine, } \\
\text { phosphoric acid and water) } \\
\text { super molecular crystal [10] } \\
\begin{array}{c}\text { Glycine picrate [11] } \\
\text { CdCl }{ }_{2}(\mathrm{TPPO})_{4}\end{array}\end{array}$ & $\mathrm{P} 2_{1} / \mathrm{a}{ }_{1} / \mathrm{c}$ & 0.02 \\
{$[\mathrm{present}$ work] } & $\mathrm{P} 2_{1} / \mathrm{a}$ & 3.1 \\
\hline
\end{tabular}

material was confirmed by EDAX analysis. The functional groups were identified using FTIR analysis. The UV-Vis-NIR spectrum reveals the wider transmission window of $\mathrm{CdCl}_{2}$ (TPPO) $)_{4}$. Thermal analysis indicates that $\mathrm{CdCl}_{2}(\mathrm{TPPO})_{4}$ is thermally stable upto $\sim 573 \mathrm{~K}$. The powder SHG efficiency of this $\mathrm{CdCl}_{2}$ (TPPO) $)_{4}$, a centrosymmetric crystal is $\sim 0.94$ times that of the efficiency of KDP and can be used in photonics device fabrication. The mechanical stability of $\mathrm{CdCl}_{2}$ (TPPO) $)_{4}$ has been determined using Vickers microhardness studies.

\section{REFERENCES}

[1] J. Zyss, J. F. Nicoud and M. Coquillay, "Chirality and Hydrogen Bonding in Molecular Crystals for Phase Matched Second Harmonic Generation: N-14-Nitrophenyl-(L)-Prolinol(NPP)," Journal of Chemical Physics, Vol. 81, No. 9, 1984, p. 4160. doi:10.1063/1.448134

[2] C. Elschenbroich and A. Salzer, "Organometallics: A Concise Introduction," 2nd Edition, Wiley-VCH, Weinheim, 1992.

[3] H. O. Marcy, L. F. Warren, M. S. Webb, C. A. Ebbers, S. P. Velsko, G. C. Kennedy and G. C. Catella, "Second
Harmonic Generation in Zinc Tris(Thiourea) Sulfate," Applied Optics, Vol. 31, No. 24, 1992, pp. 5051-5060. doi:10.1364/AO.31.005051

[4] J. A. Gadsden, "Infrared Spectra of Minerals and Related Inorganic Compounds,” Butterworths, London, 1975.

[5] L. Li., Z. P. Wang, G. R. Tian, X. Y. Song and S. X. Sun, "Growth and Properties of Dichloro bis(Triphenylphosphine Oxide)Zinc(II), a Novel Nonlinear Optical Crystal," Journal of Crystal Growth, Vol. 310, No. 6, 2008, pp. 1202-1205. doi:10.1016/j.jcrysgro.2007.12.058

[6] K. Sreevani, K. Thangaraj, K. Ramamurthi, S. Selvanayagam and K. Ravikumar, "Crystal Growth and Characterization of Dibromo Bis(Triphenyl Phosphine Oxide)Cadmium II," Journal of Crystal Growth, Vol. 322, No. 1, 2011, pp. 78-83. doi:10.1016/j.jcrysgro.2011.03.018

[7] P. M. Ushasree, R. Jayavel, C. Subramanian and P. Ramasamy, "Nonlinearity of KDP," Bulletin of Electrochemistry, Vol. 14, 1998, pp. 407-410.

[8] S. K. Kurtz and T. T. Perry, "A Powder Technique for the Evaluation of Nonlinear Optical Materials," Journal of Applied Physics, Vol. 39, No. 8, 1968, pp. 3798-3813. doi:10.1063/1.1656857

[9] K. E. Reickhoff and W. L. Peticolas, "Optical Second-Harmonic Generation in Crystalline Amino Acids," Science, Vol. 147, No. 3658, 1965, pp. 610-611. doi:10.1126/science.147.3658.610

[10] W. S. Guo, F. Guo, C. S. Wei, Q. T. Liu, G. Y. Zhou, D. Wang and Z. S. Shao, "SHG from Centrosymmetric Supermolecular Crystal," Science in China Series B: Chemistry, Vol. 45, No. 3, 2002, pp. 267-243.

[11] S. K. M. Shakir, K. K. Kushwaha, K. Maurya, M. Arora and G. Bhagavannarayana, "Growth and Characterization Of Glycine Picrate-Remarkable Second-Harmonic Generation in Centrosymmetric Crystal," Journal of Crystal Growth, Vol. 311, No. 15, 2009, pp. 3871-3875. 